Revista Aspas

ppgac - USP

Artigo

\title{
O CORPO MATERNO COMO PROVOCAÇÃO ENTRE O PÚBLICO E O PRIVADO
}

\author{
THE MATERNAL BODY AS A PROVOCATION \\ BETWEEN PUBLIC AND PRIVATE
}

EL CUERPO MATERNO COMO PROVOCACIÓN ENTRE EL PÚBLICO Y EL PRIVADO

Mariela Lamberti de Abreu

Mariela Lamberti de Abreu Atriz e pesquisadora, graduada em Psicologia pela Universidade Estadual de Maringá (UEM) e mestranda no PPG de Artes Cênicas da Escola de Comunicações e Artes da Universidade de São Paulo (ECA-USP). 


\begin{abstract}
Resumo
O artigo se propõe a pensar na dualidade público-privado sob a ótica da crítica feminista, inclusive questionando essa separação e apresentando diferentes argumentos de algumas autoras. Com isso, pretende-se encontrar pontos de interseção com uma performance artística criada também para provocar e questionar as paredes que separam a casa da rua, que põe a mulher quase como refém da lógica das teorias políticas liberais, hierarquizando a vida pública e a vida privada com critérios bastante segregadores.
\end{abstract}

Palavras-chave: Corpo Materno, Público, Privado, Feminismo.

\title{
Abstract
}

The article aims to reflect on the public-private duality from the perspective of the feminist critique, as well as questioning this separation and presenting different arguments from some female authors. From this point onwards, this study tries to find similarities with an artistic performance also created to provoke and question these walls built to separate the house environment from the street, placing women almost as a hostage of politically liberal logics, and prioritizing public and private life with some very segregate criteria.

Keywords: Maternal Body, Public, Private, Feminism.

\section{Resumen}

El artículo se propone a pensar en la dualidad público-privado bajo la óptica de la crítica feminista, incluso cuestionando esa separación y presentando diferentes argumentos de algunas autoras. A partir de esto, se pretende encontrar puntos de intersección con una actuación artística creada también para provocar y cuestionar estas paredes que separan la casa de la calle, colocando a la mujer casi como una rehén de las lógicas de las teorías políticas liberales y jerarquizando la vida pública y la vida privada, con criterios bastante segregados.

Palabras clave: Cuerpo Materno, Público, Privado, Feminismo.

Segundo Margareth Rago (1998), a participação feminista na crítica teórica, cultural e epistemológica - juntamente com a psicanálise, a teoria crítica marxista e o pós-modernismo - revela o caráter de categorias dominantes, que se apresentam como universais, e propõe uma crítica também da racionalidade 
burguesa que não se percebe como criação masculina, e logo, excludente. Denuncia ainda a ideia de identidade sem ser possível pensar a diferença, e a partir disso, pode-se afirmar que o feminismo flerta com o pensamento pós-moderno, com a crítica do sujeito e com as formulações de Foucault e Derrida.

Um ponto importante da crítica feminista é o conceito universal de homem, que automaticamente remete-se ao heterossexual, branco, civilizado, enfatizando seu caráter ideológico, racista e sexista. Com esse pensamento tem-se a lógica de que as práticas masculinas são mais valorizadas e hierarquizadas em relação às práticas femininas, e, consequentemente, $o$ mundo privado de menor importância quando comparado à esfera pública.

A partir dessa crítica e da denúncia feminista sobre às relações de poder baseadas no gênero, algumas teóricas propuseram que o sujeito deixasse de ser tomado como ponto de partida para as teorias, e que fosse considerado como resultado das determinações culturais, com complexas relações sociais, sexuais e étnicas. Com isso, a teoria de gênero foi encontrando espaço favorável para ser discutida, com a lógica de que o sexo é natural, e o gênero é socialmente construído. Essa ideia funciona como um pilar da política feminista, embora Judith Butler (2010) tenha apresentado críticas bastante pertinentes em relação a este determinismo, justificando que neste caso a cultura seria então o destino. Grosso modo, Butler (2010) problematiza a distinção gênero-sexo e a identidade "das mulheres" como categoria a ser representada pelo feminismo.

A filosofia pós-moderna propõe novas relações para descontruir as identidades supostamente "naturais," em busca de uma totalização das multiplicidades, e defende a noção de que o discurso produz a realidade - pensamento que coincide com a crítica da unidade do sujeito, apontada por Butler (2010). Seguindo essa corrente, as teóricas feministas apoiam que o sujeito "mulher" não pode ser pensado como uma identidade biológica construída culturalmente em meio à relações sociais e sexuais, práticas disciplinadoras e discursos instituintes. O discurso então é visto como prática, proporcionando múltiplos significados. É nesse contexto que Joan Scott ${ }^{1}$, citada por Margareth

1. Historiadora norte-americana. Inspirada nos pensamentos de Foucault e Derrida, propôs uma nova forma de se pensar gênero a partir de uma crítica à concepção de sexo-gênero, que, em sua opinião, não eram suficientes para historicizar a categoria sexo e o corpo, e chama a atenção para a necessidade de se pensar na linguagem e discursos constituintes e sair do pensamento dual que recai na dicotomia homem/mulher, masculino/feminino. 
Rago (1998), enfatiza a importância do discurso na questão socioeconômica e vê a divisão sexual do trabalho como efeito dele, criticando a oposição entre o lar e o trabalho, que obriga as mulheres a optarem entre o trabalho doméstico e o assalariado. Analisando Scott, Rago (1998) entende que o discurso masculino, responsável pela ideia de inferioridade física e mental das mulheres, definiu a divisão "aos homens, a madeira e os metais" e "às mulheres, a família e o tecido", causando, assim, a divisão sexual da força de trabalho, posicionando as mulheres numa hierarquia laboral inferior, com salários insuficientes para seu sustento.

A filósofa política Susan Okin (2008), em seu artigo Gênero, o público e o privado, se propõe justamente a discutir a dicotomia público-privado, analisando seus significados a partir de uma perspectiva de gênero, apesar de considerar que estes conceitos ainda continuam sendo usados pela teoria política como se não fossem problemáticos, divergindo da teoria feminista, que aponta várias questões a respeito dessa divisão. A autora justifica que frequentemente se aceita a ideia de que essas esferas são separadas e diferentes, a ponto do público e político poderem ser discutidos de forma isolada em relação ao privado ou pessoal.

Conforme os estudos de gênero foram ganhando terreno, esta nova categoria de análise no campo da teoria feminista gerou questões sobre as distinções inquestionáveis entre privado e público, e o termo "gênero" passou a ser utilizado para compreender não apenas a desigualdade sexual, mas também as diferenciações sexuais como socialmente construídas.

Os estudos feministas demonstram uma inquietação em relação às ambiguidades envolvidas nas discussões sobre o público e o privado, por exemplo, em casos em que essa dicotomia refere-se a Estado e sociedade, ou para se referir à divisão entre vida não doméstica e vida doméstica. Tem-se perpetuado a lógica de que Estado se relaciona a público, enquanto a família e a vida íntima estão relacionadas ao privado.

Okin (2008) propõe-se a focar nessa dicotomia, pois entende que é desse modo que os teóricos leem a família, ignorando sua natureza política e a relevância da justiça na vida pessoal dos sujeitos, o que pode ser percebido como o centro dos problemas relacionados às desigualdades de gênero. Essa característica é herdada das práticas e teorias patriarcais do passado, 
e tem muitas consequências práticas principalmente para as mulheres, como é evidente.

A divisão sexual do trabalho tem alimentado essa dicotomia, uma vez que os homens são relacionados às ocupações da vida política e econômica, enquanto as mulheres são vistas como naturalmente inaptas à esfera pública, sobrando para elas então as ocupações da esfera privada, responsabilidades domésticas e reprodução, e, desse modo, dependem dos homens para seu sustento.

O julgamento de que a família é não-política se sustenta no fato de que ela não entra nas discussões da maioria dos estudos atuais sobre teoria política, desconsiderando a hierarquia de poder que nela se dá, a divisão de trabalho injusta e a dependência econômica que isso causa. Portanto, as análises feministas sobre gênero vieram para contribuir e provocar a teoria política contemporânea e afetar a lógica da dualidade público-privado, apontando suas falhas.

Algumas teorias feministas focadas em gênero justificam que as práticas políticas e econômicas afetam diretamente as estruturas da esfera doméstica, argumentando que o pessoal é também político, o que significa que o que acontece na vida pessoal está diretamente relacionado à estrutura e hierarquia de poder identificada na esfera política, e portanto, esta não pode ser interpretada de forma isolada em relação àquela, já que o Estado ao mesmo tempo influencia e define a vida doméstica.

O movimento feminista dos anos 1960 pretendia derrubar as barreiras contra a mulher no aspecto do trabalho e política, além de sustentar que a mulher tinha sim responsabilidades sobre a família. Já as feministas radicais entendiam que, se a família era a fonte de opressão, ela deveria ser extinta. Isso proporcionou divisões dentro do movimento, visto que algumas recusavam a divisão sexual do trabalho, mas não aceitavam também abrir mão da família. Desde então, a família tem sido colocada no centro dos estudos políticos do feminismo. As teorias feministas contemporâneas vêm desafiando o julgamento de que a vida pessoal e familiar é tão separada da esfera social, questionando assim a maioria das teorias políticas. É evidente que existem algumas distinções acerca do público e do privado que devem ser consideradas, visto que algumas reivindicações feministas associadas aos direitos reprodutivos são baseadas no direito da mulher a vários tipos de privacidade. 
Segundo Okin (2008) muitas feministas defendem que alguns fatores centrais nas questões de gênero, como a divisão doméstica do trabalho e a responsabilidade da mulher na criação dos filhos, são ideias socialmente construídas, portanto, aspectos da estrutura social e política. Assim, é impossível explicar essa lógica sem fazer referência à esfera pública, como a discriminação sexual no trabalho, o pequeno número de mulheres ocupando cargos políticos relevantes e o pensamento vigente de que os trabalhadores e políticos não devem ser responsáveis por cuidar dos filhos.

Citando a pesquisa psicanalítica de Nancy Chodorow ${ }^{2}$ a respeito do desenvolvimento psicológico de crianças de ambos os sexos criadas por mulheres - visto que nossa sociedade é estruturada pelo gênero - e os diferentes efeitos dessa criação na personalidade das crianças, Okin (2008) pontua alguns aspectos bastante interessantes sobre o porquê são as mulheres que desempenham o papel de cuidadora nos primeiros anos de vida da criança, não apenas do ponto de vista psicológico dos sexos, mas também na explicação da segregação sexual nos ambientes de trabalho, em que a maioria das mulheres ainda ocupam cargos desprivilegiados e com menores salários. Este fato funciona como uma justificativa econômica em relação a qual genitor seria o mais adequado a se manter dentro de casa, responsável pelas funções domésticas e criação dos filhos, alimentando este ciclo.

Nessa busca pela compreensão do gênero, as feministas detectaram que o tempo todo o público e o doméstico se misturam, se interceptam, de forma a ser cada vez mais difícil dissociá-los completamente, expondo as faIhas das teorias políticas que ignoram estes aspectos. Não se pode entender a esfera política sem levar em consideração que ela é definida pelo gênero, e foi construída a partir da ideia de superioridade e dominação masculina, pressupondo como "natural" a responsabilidade doméstica da mulher.

Existe também a noção de privacidade no interior da própria família, apoiada por feministas e defensoras dos direitos das crianças, que proporciona proteção aos membros da família, individualmente, mesmo contra as exigências ou preferências dos seus membros com mais poder. Podemos citar como exemplo as decisões em relação ao aborto e à contracepção como

2. Socióloga e psicanalista feminista norte-americana. 
um direito individual, independentemente de decisões coletivas internas no núcleo familiar.

Okin (2008) apresenta um outro argumento sobre a importância da privacidade dentro da esfera doméstica, que seria uma fuga da tensão que existe em relação aos vários papéis sociais desempenhados pelos sujeitos, e que é muito mais raramente possível para as mulheres, pois espera-se muito mais delas em seu papel doméstico de ser responsável pela família. Esse argumento defende que a privacidade é útil para o autodesenvolvimento mental, evidenciando a importância da solidão e da oportunidade de se concentrar. Mas, infelizmente, isso também está bem menos disponível para as mulheres, como já notaram algumas feministas. A autora comenta que para os homens, o fato de ter uma família é menos conflitivo com suas realizações artísticas e criativas do que para as mulheres, e é muito comum que as mulheres sintam que é preciso escolher entre estas opções, pois de forma geral, é muito difícil que uma mulher seja bem sucedida em seu trabalho, em seu relacionamento com o parceiro e com os filhos, sem prejuízo em nenhum destes aspectos.

Okin (2008) deixa clara sua posição sobre a necessidade de privacidade, tanto para homens como para mulheres, para desenvolverem suas relações íntimas, para conseguirem se afastar temporariamente de seus papéis sociais e para que tenham a oportunidade de ficarem sozinhas, desenvolvendo sua mente e criatividade. Ademais, alerta que para que isso seja possível, as práticas de gênero deverão ser alteradas para que existam oportunidades iguais às dos homens, seja para fazerem parte da esfera da política e do trabalho, seja para terem as vantagens que a privacidade tem a oferecer.

\section{O corpo materno em performance}

Questionando a lógica da produtividade, evidenciada na dualidade público-privado principalmente quando se leva em conta a questão de gênero, e consequentemente, a referida incompatibilidade de sucesso nas duas esferas, a performer brasileira Roberta Barros ${ }^{3}$ propôs uma intervenção artística após dar à luz sua segunda filha.

3. Artista visual, mestre e doutora em Artes Visuais pela Universidade Federal do Rio de Janeiro (UFRJ) e professora na Universidade Cândido Mendes. 
Em seu livro Elogio ao toque, ou como falar de arte feminista à brasileira, a autora relata que durante sua entrevista para o processo seletivo do doutorado em 2009 o tempo dispensado a ela foi bem maior em relação aos outros candidatos, e que, curiosamente, as perguntas feitas pelos examinadores giravam em torno de suas estratégias para garantir o aleitamento de seu bebê que naquele momento ainda estava na barriga - enquanto estivesse cumprindo os créditos das disciplinas. Segundo ela, além dessas perguntas, os examinadores também fizeram questão de enumerar diversos casos de insucesso de outras mulheres que se propuseram multiplicar entre a casa e a rua.

Nesta situação fica escancarado que o privado sempre foi público, e o quanto as ações políticas e as produções de saberes interferem nas decisões da intimidade, invadindo espaços até mais íntimos do que as casas: os corpos.

A partir disso, Roberta Barros (2016) planejou sua performance Dar de Si, um trabalho de ordenha performática de seu próprio leite para oferecer aos espectadores, questionando a "escravização desse corpo materno".

Antes de descrever sua performance e seus efeitos, a autora contextualiza algumas reivindicações feministas que esbarram na separação entre a casa e a rua, e aponta algumas diferenças entre o movimento feminista norte-americano e europeu e a forma como ele chegou ao Brasil. Segundo ela, mulheres norte-americanas e europeias lutavam pela autonomia feminina enfatizando as decisões sobre o próprio corpo, levando à esfera pública reivindicações consideradas antes como pertencentes à vida privada. Enquanto isso, as feministas brasileiras, em outro contexto político, durante o golpe militar, lutavam contra o autoritarismo e acabaram por juntar forças a partidos políticos, associações de esquerda e a alguns setores progressistas da Igreja Católica, fazendo com que suas reivindicações se concentrassem em metas coletivas, como a defesa dos direitos humanos, da liberdade política e das melhorias das condições sociais de vida. A aliança com a Igreja permitiu às mulheres atitudes de militância $e$ resistência, embora potencializasse o espaço doméstico da família, ameaçado pela repressão, politizando assim o papel tradicional da mãe. Em contrapartida, essa associação com a Igreja fez com que os debates sobre temas feministas centrais ficassem de lado, como a liberação sexual, o direito ao aborto e ao divórcio. Este atraso em relação às reivindicações se reflete até hoje no 
movimento feminista brasileiro, em suas bandeiras de reivindicações, na representação da mulher e no papel da mulher na arte.

A partir da década de 70, o movimento feminista, principalmente europeu e norte-americano, transbordou para o mundo da arte, e as mulheres começaram a usar seus corpos em performances, vídeos e fotografias ao invés de continuarem a servir de modelo em obras de artistas homens. $\mathrm{O}$ corpo feminino, tão explorado e representado na cultura ocidental, passou a ser percebido como uma arma potente e usado pelas militantes em suas manifestações políticas.

A aproximação entre arte e feminismo evidencia a relação entre as demandas das políticas feministas e as elaborações estéticas de artistas que foram influenciadas por tais inquietações. Nesse sentido, para realizar sua performance, Roberta Barros investigou os conceitos de corpo feminino, corpo pós-feminista e corpo materno, para então propor que o corpo feminista seja uma fronteira que não se fixe, mas que busque estratégias de desenraizamentos e de desencontros com o corpo biológico, por exemplo. A artista enfatizou os conceitos de abjeto, erotismo, pornográfico para buscar essa experiência, contrapondo às identidades fixas de corpo.

$\mathrm{Na}$ criação $\mathrm{Dar}$ de $\mathrm{Si}$, realizada em agosto de 2011, a partitura planejada pela artista era de entrar na sala, despir o torso, se ajoelhar, ordenhar os dois seios guardando o leite que caísse em copos de vidro simples, e depois oferecer todo seu leite aos espectadores. Para isso, por cerca de 12 horas antes da performance ficou sem amamentar, para que o leite se acumulasse.

A artista, então, se apresenta aos espectadores com um vestido longo de linho branco, se ajoelha, e aos poucos abre os botões do vestido, revelando seu sutiã sem rendas nem qualquer outro apelo fetichista, que também passa a ser aberto, expondo os seios. Ela então alcança um copo de vidro pequeno, transparente e simples que estava próximo ao seu corpo, e sem cerimônia nem suspense começa a apalpar o seio. Um primeiro esguicho do líquido branco foi derramado no copo, e conforme o recipiente foi sendo preenchido, o som ritmado ia ganhando volume. Durante os esguichos algumas gotas escapavam do copo, molhando a roupa e marcando o contorno das coxas da artista. Em cerca de oito minutos o copo estava pela metade, e entre os movimentos dramáticos do vai e vem do torso da artista podia-se ver prazer na expressão facial dela. 
A performance contrapõe a imagem da mãe virginal, tão comumente representada na arte ocidental, num transbordamento entre maternidade e gozo, neste ato tão feminino de alimentar. Ela comenta que, sem a filha pendurada nela, no típico contorno do corpo mãe-bebê, não havia vedação que segurasse ou escondesse o líquido corpóreo entre os mundos externo e interno.

O indefinível prazer sereno de alimentar a cria, de desempenhar o papel materno, o gozo e o poder de gerar e manter uma vida, a satisfação paradoxalmente extraída desse ato escravizante de pura entrega esbarram ali na dor do desperdício. O desperdício proporcionou-me o alívio imediato por esvaziar-me de uma dor e autorizou o toque dos seios de um modo lascivo, usualmente interditado no corpo da mulher-mãe. (BARROS, 2016, p. 221)

A artista relata que durante essa falta de controle sobre o tempo neste ato de doação, na fronteira entre delicadeza e violência, penitência e gozo, os limites físicos e morais foram chegando à superfície de forma perturbadora, fazendo com que todos os presentes experimentassem algo entre desejo e repulsa, chegando ao ponto de algumas pessoas deixarem a sala.

Depois de cerca de 27 minutos de ordenha da mama direita, esta ficou murcha enfim, e o corpo assumiu um ângulo que permitia aos espectadores notarem a desproporção de tamanhos entre os seios, potencializando a assimetria do corpo, tão exaltada pela arte e pela estética feminina.

A artista então pegou outro copo, tal qual o primeiro, sua mama estava rígida e carregada, com nódulos endurecidos, e por isso foram necessários movimentos circulares e as duas mãos livres para massagear o seio com mais violência, para então retornar à ordenha. Depois de 12 minutos nessa atividade, o copo ainda possuía bem menos leite acumulado do que a metade do primeiro seio. Roberta Barros estava visivelmente exausta, quase não conseguindo se sustentar, e então deixou a sala.

A falta de controle experimentada por ela tem relação com a posição escolhida, ficar de joelhos, com o intuito de problematizar a construção da imagem da mulher-mãe como virgem-devota-santa, para denunciar a operação de beatificação, e para se aproximar da arte da performance dos anos 70 , com experimentação dos limites físicos do corpo. 
A performer relata que após sair da sala, ao ar livre, recuperando-se do cansaço e aliviando a pele, questionou-se sobre sua intenção de ofertar o leite à plateia. Percebeu que ao pousar o copo no chão, em vez de entrega-lo a alguém, manteve-o muito próximo ao corpo, como uma espécie de apego a esse leite, cujo desprendimento tinha sido tão dolorido. Quando, enfim, voltou à sala, o leite já não estava mais lá.

Refletindo sobre essa partitura interrompida de sua criação, ela conta que, desde o início da concepção da performance, já tinha o receio de que isso não iria se concretizar, tendo em vista que num mundo pós-aids as pessoas se preservam da absorção de fluidos corpóreos alheios. Ressalta, porém, que até então não suspeitava da aproximação do leite materno com a abjeção.

Segundo Barros (2016), existe uma relação de estranhamento e intimidade no abjeto, e nesse sentido, o leite é algo tão íntimo para a mãe e para o bebê, que com a fusão que se dá na amamentação, forma-se um corpo estendido, um contorno corporal, em que o líquido branco flui sem quedas e sem ser visto. A partir do momento que não existe o corpo do bebê, e que a boca não está lá para tapar os orifícios e esconder o líquido dos olhos de outros, a intimidade é transformada em estranhamento, um corpo que ora se mostra como sensual, ora causa repulsa. A ausência do bebê faz com que a atenção se volte ao corpo da mulher, e então há a percepção clara do prazer erótico envolvido no toque e nas trocas de fluidos.

A autora comenta sobre como o corpo feminino é visto como sinônimo de corpo materno, e corpo materno como assexual, como se todo o toque que é reprimido fosse autorizado apenas para a mulher-mãe.

Butler (2010) em Problemas de Gênero, tece algumas críticas a Julia $\mathrm{Kristeva}^{4}$, a partir de uma perspectiva foucaultiana, por fixar o corpo materno no lugar de poder, e por não ter percebido como esse corpo feminino que ela buscou elaborar seria ele próprio produzido pela lei paterna que produz o desejo de dar à luz. Butler argumenta que a produção discursiva do corpo materno como pré-discursivo funcionaria como um mecanismo de ocultação das relações de poder que formam a construção cultural do corpo feminino

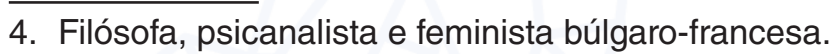


como corpo materno, e que praticamente impõe às mulheres o destino de se reproduzirem.

Roberta Barros (2016) problematiza que a mulher, para assumir o papel da santa que dá a vida, aceita o pacto de renunciar ao prazer, sendo reduzida quase à impotência sexual, garantindo esse "poder" único de reprodução para compensar o não partilhamento de outros poderes, os da participação na esfera pública. Este contrato tem sido rejeitado por muitas mulheres na contemporaneidade, seja por não querer se tornar mãe, seja por tornar-se mãe sem abrir mão da vida social separada pelas paredes de casa.

Nessa tendência de renúncia da maternidade como uma espécie de bandeira, há a substituição do corpo natural pelo corpo construído culturalmente sob a lei do risco da sociedade da concorrência, e se adia a ideia de Butler de que a mulher não deve sacrificar um de seus prazeres pelo outro, e não deve se identificar com nenhum deles em particular.

Portanto, segundo algumas feministas, a estratégia de recusa à maternidade, que poderia parecer uma rejeição do contrato de divisão de poderes, acaba por reafirmar a lógica da produtividade que se espera da vida pública e privada. Desse modo, o papel de alimentar a cria, que foi destinado às muIheres desde sempre parece incompatível com o mundo do trabalho em uma sociedade como a nossa, em que se é cobrado o tempo todo ótimo desempenho e produtividade.

Para Barros (2016), toda a fixação e exploração do "eu", evidente em sua performance, assim como em outras performances de artistas feministas, se mostra como uma estratégia bastante eficiente na medida em que a tática militante do feminismo se move sob a bandeira, já citada aqui, "o pessoal é político". Assim, a arte feminista coloca a mulher, com seu corpo e sua subjetividade, para reivindicar o poder de representar, expor e sexualizar seu próprio corpo.

Em meio ao processo de empoderamento feminista pela politização da vida privada, tão caro às práticas das décadas de 60 e 70, este narcisismo colocou foco na exposição da intimidade na esfera pública, marcando aspectos políticos do corpo. Dessa forma, para a maioria das artistas feministas desse período, cujo ativismo era o centro de suas ações, foi decisiva a ideia de politizar as experiências pessoais do sujeito feminino. 


\section{Referências bibliográficas}

BARROS, Roberta. Elogio ao toque, ou como falar de arte feminista à brasileira.

Rio de Janeiro: Editora do Autor, 2016.

BUTLER, Judith. Problemas de gênero: feminismo e subversão da identidade. Trad.

Renato Aguiar. 3. ed. Rio de Janeiro: Civilização Brasileira, 2010.

RAGO, Margareth. Epistemologia feminista, gênero e história. In: PEDRO, Joana; GROSSI, Miriam (org.). Masculino, feminino, plural: gênero na interdisciplinaridade. Florianópolis: Ed. Mulheres,1998.

OKIN, Susan Moller. Gênero, o público e o privado. Revista de Estudos Feministas, Florianópolis, v. 16, n. 2, p. 305-332, 2008.

Recebido em 13/03/2018

Aprovado em 24/08/2018

Publicado em 25/10/2018 